\title{
Superior Thoracic Aperture
}

National Cancer Institute

\section{Source}

National Cancer Institute. Superior Thoracic Aperture. NCI Thesaurus. Code C139564.

The superior opening of the thorax whose marg in comprises the upper border of the first thoracic vertebra, the first ribs, and the manubrium. 